\title{
Apparent diffusion coefficient quantification as an early imaging biomarker of response for unresectable infiltrative hepatocellular carcinoma
}

\author{
Ali Kemal Sivrioglu, ${ }^{1}$ Kemal Kara, ${ }^{2}$ Cahit Kafadar, ${ }^{2}$ Hakan Mutlu ${ }^{2}$ \\ ${ }^{1}$ Division of Radiology, Kasımpaşa Military Hospital, Istanbul, Turkey \\ ${ }^{2}$ Department of Radiology, GATA Haydarpasa Training Hospital, Istanbul, Turkey
}

We have read the interesting article of Kokabi et al., titled "Apparent diffusion coefficient quantification as an early imaging biomarker of response and predictor of survival following yttrium-90 radioembolization for unresectable infiltrative hepatocellular carcinoma with portal vein thrombosis" which was published in the April 2014 issue of the journal [1]. The study included fairly important information which was very useful for us. However, we would like to make a few contributions.

In the materials and methods section of the above article, it was mentioned that $\mathrm{b}$ values were taken as 50 , 400 and $800 \mathrm{sn} / \mathrm{mm}^{2}$ for the diffusion-weighted imaging (DWI) scans. In some MRI scanners, ADC values are calculated with regard to $\mathrm{b} 0$ and the other $\mathrm{b}$ values automatically, without the need to input b 0 value particularly. However, according to our own experiences with respect to the MRI scanner used in this study, whether $\mathrm{b} 0$ value input is requested to the scanner or not, it will calculate ADC values as regards b 50 and $800 \mathrm{sn} / \mathrm{mm}^{2}$ values directly as well as in this article. In this case, acquired ADC values will be different from the ADC values which are calculated according to $\mathrm{b} 0$ and $800 \mathrm{sn} / \mathrm{mm}^{2}$ values. It was not indicated in this article clearly, whether $\mathrm{b} 0$ value was not acquired and whether ADC quantification was made according to b 50, 800 values, or it was made according to b 0,800 values without any mention of b 0 value. This situation leads to misunderstanding and errors.
In the current article, ADC values of lesions were analysed by placing large region of interests (ROI) at a single slice. In our opinion, if mean ADC values were measured at all slices where tumour could be seen and these values were averaged, then ADC quantification would be better and more accurate. However, this technique would involve spending more time, and its routine usage in practice would be quite laborious.

Quantification of minimum ADC values instead of mean ADC values at lesions' ROI measurement would demonstrate residual tumour better and probably give different and more accurate results. This situation is parallel to the usage of maximum standard uptake values at PET/CT. Besides, it was not mentioned in the cited article whether ROI measurements excluded calcification, and whether haemorrhage areas inside the lesions were present before or they became evident after the treatment, since they could reduce ADC values [2]. This situation should be discussed in limitations, of which quite a few were mentioned in the article.

\section{References}

1. Kokabi N, Camacho JC, Xing M, et al. (2014) Apparent diffusion coefficient quantification as an early imaging biomarker of response and predictor of survival following yttrium-90 radioembolization for unresectable infiltrative hepatocellular carcinoma with portal vein thrombosis. Abdom Imaging 39:969-978

2. Mutlu H, Sivrioglu AK, Sonmez G, et al. (2012) Role of apparent diffusion coefficient values and diffusion-weighted magnetic resonance imaging in differentiation between benign and malignant thyroid nodules. Clin Imaging 36(1):1-7 